
\title{
R Reseracth Sulure \\ Relationship between advancing abutment pressure and deformation of surrounding rock in a roadway: A case study in Helin coal mine in China
}

\author{
Hongyan Qin \\ NCIST \\ Zhiheng Cheng ( $\sim$ an958158@163.com ) \\ NCIST \\ Zhenhua Ouyang \\ NCIST \\ Xidong Zhao \\ NCIST \\ Jicheng Feng \\ $\mathrm{NCIST}$
}

\section{Research Article}

Keywords: Fully-mechanized caving mining, Advancing abutment pressure, Roadway deformation, Relationship between stress and deformation

Posted Date: March 19th, 2021

DOI: https://doi.org/10.21203/rs.3.rs-161262/v1

License: (c) (1) This work is licensed under a Creative Commons Attribution 4.0 International License.

Read Full License

Version of Record: A version of this preprint was published at Environmental Earth Sciences on November 1st, 2021. See the published version at https://doi.org/10.1007/s12665-021-10045-6. 


\title{
Relationship between advancing abutment pressure and deformation of
}

\section{surrounding rock in a roadway: A case study in Helin coal mine in China}

\author{
Hongyan Qin ${ }^{1,2}$, Zhiheng Cheng ${ }^{1,2,3 *}$, Zhenhua Ouyang ${ }^{1,2 *}$, Xidong Zhao ${ }^{1,2}$, Jicheng Feng ${ }^{1,2}$ \\ ${ }^{1}$ North China Institute of Science \& Technology, Beijing, China \\ ${ }^{2}$ Key Laboratory of Mine Disaster Prevention and Control in Hebei Province, Langfang, Hebei, China \\ ${ }^{3}$ NCIST Zhongan Technology (Beijing) Co., LTD, Beijing, 101601, China \\ *Corresponding author. E-mail: an958158@163.com and oyzhua@163.com
}

\begin{abstract}
The deformation stages of the working face of a mine in front of the roadway were defined based on the location of the roadway and the coal wall in different deformation zones. Observational data of the advancing abutment pressure and the surrounding rock deformation of the roadway from Helin coal mine were analyzed using least squares fitting. The results show that the distance between the boundary of the rapid deformation stage and the deceleration deformation stage and the position where the advancing abutment pressure is equal to the original rock stress is $0.8 \mathrm{~m}$. The distance between the boundary of the large deformation stage and the stable small deformation stage and the peak value of the advancing abutment pressure is $0.3 \mathrm{~m}$. A theoretical analysis indicated that the boundary between the rapid deformation stage and the deceleration deformation stage is located at the intersection of the advancing abutment pressure curve and the original rock stress curve. The boundary between the large deformation stage and the stable small deformation stage is located at the peak value of the advancing abutment pressure.
\end{abstract}

Keywords: Fully-mechanized caving mining; Advancing abutment pressure; Roadway deformation; Relationship between stress and deformation

\section{Introduction}

As a result of the continuous improvement of coal mining technology and mining equipment in China, large-scale mechanized caving mining has been used widely. The determination of the advancing abutment pressure of fully-mechanized caving mining and the characteristics of the deformation of the surrounding rock in the roadway is of great significance for in-depth studies of mining pressure, roadway support, and equipment selection. Studies of the advancing pressure and 
the deformation of the surrounding rock in the roadway following the methods of Qian, Song, and $\mathrm{Hou}^{[1,2]}$ have resulted in constructive achievements. $\mathrm{Xu}^{[3,4]}$ investigated the influence of the key layer on the characteristics of the mining pressure in a fully-mechanized working face. Wang ${ }^{[5,6]}$ obtained good results in a study of the influence of the caving ratio on the characteristics of the mining pressure in a fully-mechanized working face. Pan and Zhang ${ }^{[7,8,9]}$ determined key rules regarding the characteristics of the mining pressure in different areas and different mines in a fully-mechanized working face. $\mathrm{Ma}^{[10,11]}$ conducted in-depth theoretical and experimental research on the stress and failure characteristics of roadways during mining. Kang ${ }^{[12,13]}$ conducted in-depth research on roadway deformation damage and control technology and the methods are widely recognized in the industry. Gou ${ }^{[14,15]}$ investigated the mechanical processes of roadway destruction. However, few studies have been conducted on the influence of the pressure distribution on the roadway deformation and their relationship.

In this paper, a theoretical analysis and field measurements are integrated to investigate the connection between the advancing abutment pressure and the deformation of the surrounding rock in the roadway of a fully-mechanized coal mine; the j7401 working face of the Helin coal mine is used as the example.

\section{Overview of the study background}

The 7(4) coal seam in the j7401 working face of the Helin coal mine has a surface elevation of $+255 \sim+310 \mathrm{~m}$, a level elevation of $-150 \mathrm{~m} \sim-270 \mathrm{~m}$, a length of the working face of $240 \mathrm{~m}$, and an advancing direction length of $1520 \mathrm{~m}$; the inclination range of the working face is larger and the average angle of the working face is about $6^{\circ}$. The range of the coal seam thickness of the working face is $7.8 \mathrm{~m} \sim 13.6 \mathrm{~m}$ and the average thickness of the coal seam is about $11.4 \mathrm{~m}$. Because the hardness of the coal seam is relatively low, the stability is low, a 3.4-m mining height and an 8-m top coal caving height are used in the fully-mechanized top-caving coal mining. The overburden structure of the working surface is relatively simple. The top and bottom plate consist of mudstone 
and sandstone and the bottom is carbonaceous mudstone, which is black-gray with a thin, dense, and hard layer and an average thickness of $6.70 \mathrm{~m}$. The old bottom is also black and brown-gray, consists of silty sandstone that is dense and hard with an average thickness of $8.65 \mathrm{~m}$.

\section{Theoretical analysis}

Due to the existence of a beam structure, a zone of increasing stress is formed in front of the working face as mining progresses, as shown in Figure 1. Prior to the structural failure of the beams, the advancing abutment pressure increases continuously, the surrounding rock of the roadway moves closer, and the moving speed increases. ${ }^{[1,2,16,17]}$ During this process, the working face is continuously progressing. Under the influence of the advancing abutment pressure, two areas are formed in front of the working face, i.e., the plastic zone (zone A) and the elastic zone (zone B).

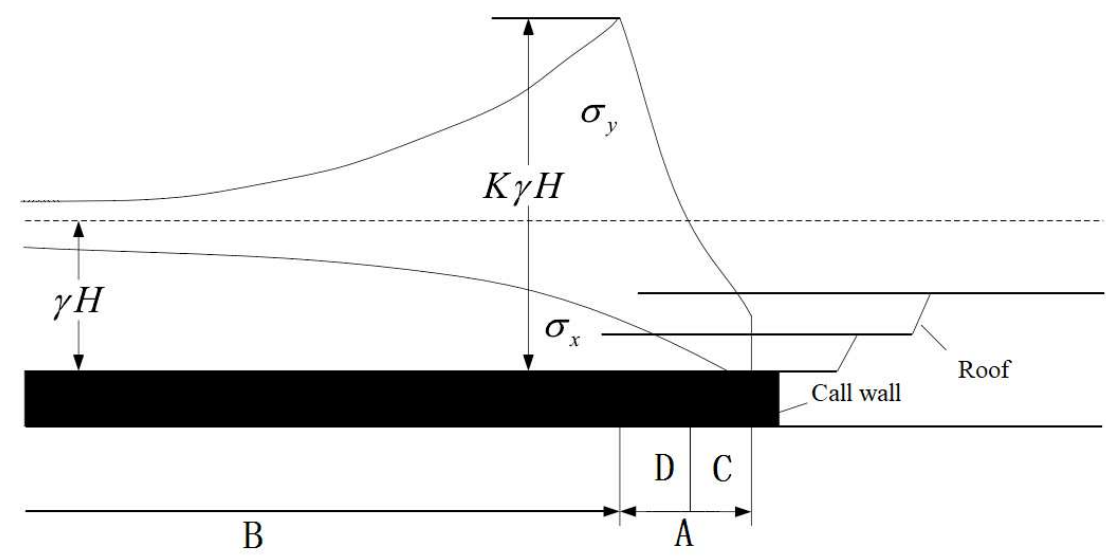

Fig. 1 Diagram of the advancing abutment pressure

The equation of the hydraulic equilibrium in the horizontal direction and vertical direction at any location in the plastic zone is:

$$
m \sigma_{x}+2 f \sigma_{y} d_{x}-m\left(\sigma_{x}+d \sigma_{y}\right)=0
$$

Where $\mathrm{m}$ is the thickness of the working face, $\mathrm{f}$ is the friction coefficient, $\sigma_{x}$ is the horizontal stress of the unit, $\sigma_{y}$ is the vertical stress of the unit.

Based on the Mohr-Coulomb criterion, equation (1) is obtained: 


$$
\sigma_{y}=2 C \sqrt{\frac{1+\sin \psi}{1-\sin \psi}}+\frac{1+\sin \psi}{1-\sin \psi} \sigma_{x}
$$

Where $C$ is the cohesion of the coal, $\psi$ is the internal friction angle of the coal.

We define $R_{\psi}=\frac{1+\sin \psi}{1-\sin \psi}, \quad R_{C}=2 C \sqrt{\frac{1+\sin \psi}{1-\sin \psi}}$

The vertical stress expression in the plastic zone can be reduced to:

$$
\sigma_{y}=N_{0} e^{\frac{2 x f R_{\psi}}{m}}, N_{0} \leq \sigma_{y} \leq k \gamma H
$$

Where $N_{0}$ is the supporting capacity of the coal wall, $k$ is the advancing stress concentration factor.

When $\sigma_{y}=k \gamma H$, the advancing abutment pressure reaches its peak and the distance between the peak position and the coal wall, $x_{0}$, is represented as:

$$
x_{0}=\frac{m}{2 f} \frac{1-\sin \psi}{1+\sin \psi} \ln \left(\frac{k \gamma H}{(C+\sigma \tan \psi) \cot \psi} \frac{1-\sin \psi}{1+\sin \psi}\right)
$$

Where $\sigma$ is the support resistance to the flank.

The peak of the advancing abutment pressure in front of the working face occurs at $x_{0} \mathrm{~m}$ and represents the boundary between the elastic deformation area (area $\mathrm{B}$ ), which is $x_{0} \mathrm{~m}$ in front of the working face and the plastic deformation zone, which is o to $x_{0} \mathrm{~m}$ in front of the working face. The plastic deformation zone is divided into the failure zone (zone C) and limit equilibrium zone (zone D) by the intersection of the advancing abutment pressure curve and the original rock stress line.

In zone $\mathrm{C}$, the coal strata that lost its integrity and has poor carrying capacity causes large and sharp deformation of the surrounding rock in the roadway; this is referred to as the rapid deformation stage of the surrounding rock of the roadway. In zone D, although the coal bed has higher integrity and bearing capacity and experiences plastic deformation, it is still in a discontinuous state. There is 
less roadway deformation in this area and the rate of deformation is slower; this is referred to as the deceleration deformation stage of the surrounding rock of the roadway. The failure zone and the limit equilibrium zone are collectively called the plastic zone with large deformation; this is called the large deformation stage.

The elastic deformation zone, where the coal rock formation is in good condition and has good bearing capacity is referred to as the stable small deformation stage. Although the roadway deformation is small in this area, it is larger than the deformation of the roadway under the original rock stress.

\section{Field test}

\subsection{Arrangement of the observation stations}

\subsubsection{Observation station of the advancing abutment pressure}

Four groups of observation stations were set up $100 \mathrm{~m}$ ahead of the $\mathrm{j} 7401$ fully-mechanized working face; each observation covered two boreholes located in the transportation roadway and the ventilation roadway respectively. The depths of the two drilling holes were $3 \mathrm{~m}$ in the first group, 6 $\mathrm{m}$ in the second group, $12 \mathrm{~m}$ in the third group, and $15 \mathrm{~m}$ in the fourth group. One borehole stress meter was placed in each borehole and was located $1.5 \mathrm{~m}$ from the floor of the mining roadway. The layout of the stress gauges and boreholes in the working face are shown in Figure 2. The observations were conducted based on the progress of the $\mathrm{j} 7401$ fully-mechanized working face. The distance between the observation point and the working face lager than $50 \mathrm{~m}$ and the observation data were recorded every two days during the morning shift. The distance between the observation point and the working face was 30 to $50 \mathrm{~m}$ and the observation data were recorded daily during the morning shift. The distance between the observation point and the working face smaller than $30 \mathrm{~m}$ and the observation data were recorded daily during the morning shift and midday shift. 


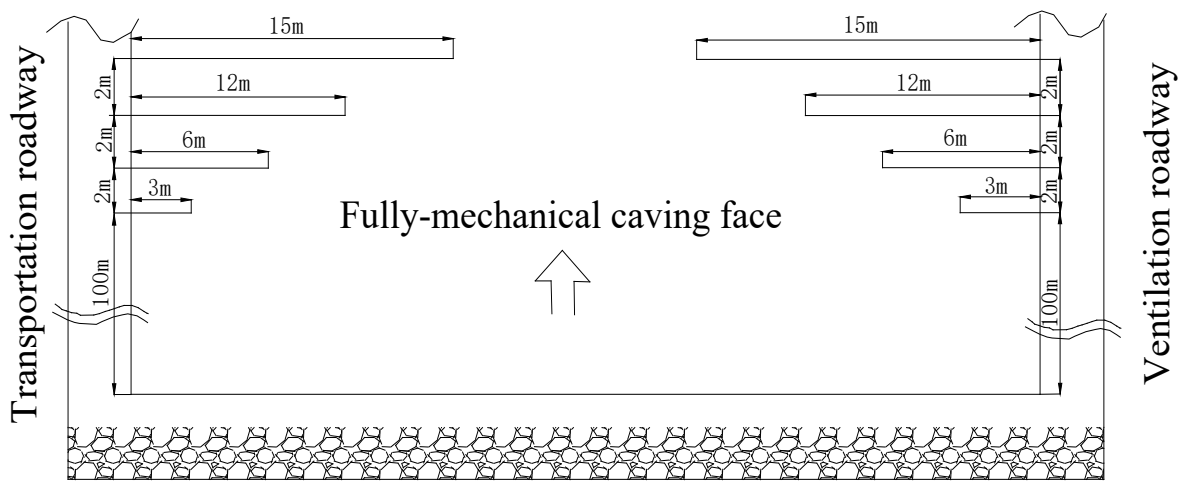

Fig. 2 Diagram of the stress drill point layout

\subsubsection{Observation station of the surrounding rock deformation}

In the fully-mechanized mining face, the deformation of the back mining roadway was observed to determine the deformation characteristics of the surrounding rock of the transport roadway and the ventilation roadway and analyze the influence of the mining on the surrounding rock deformation. Observation lines with three stations located $30 \mathrm{~m}$ apart were laid out in a cross pattern to observe the surface displacement of the mining roadway. The layout parameters of the tunnel test station are shown in Figure 3.

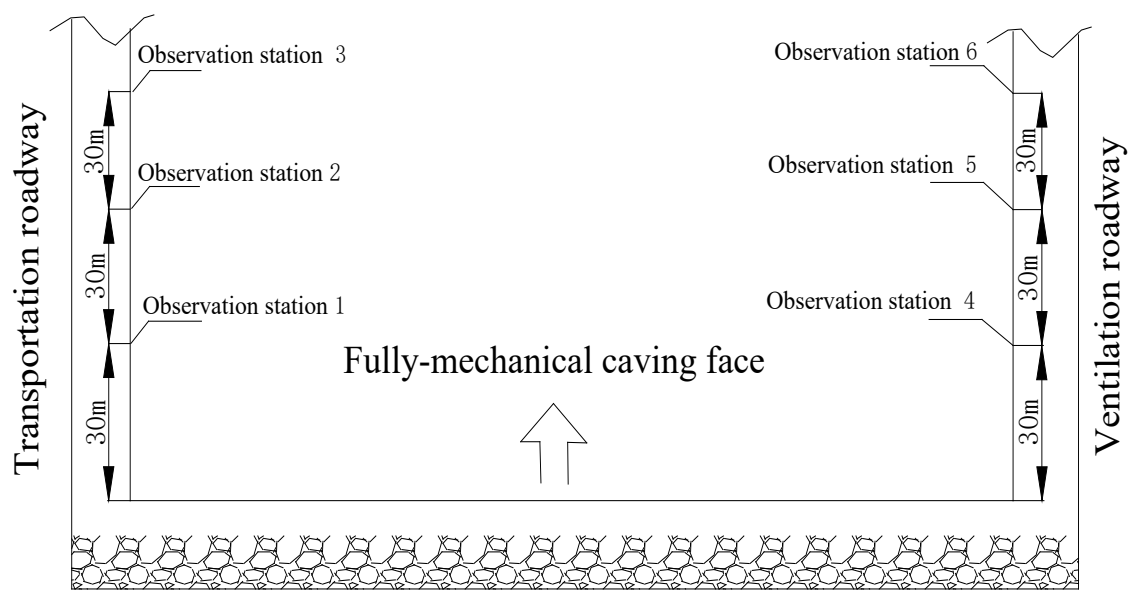

Fig. 3 Diagram of the roadway station layout

\subsection{Results and discussions}

\subsubsection{Variations in the advancing abutment pressure}

As the fully-mechanized caving face is pushed forward, the coal body is gradually deformed and broken and the borehole wall in the mining roadway is filled between the borehole and the 
borehole stress gauge. As a result, the borehole stress gauge in the roadway is in full contact with the coal body in the fully-mechanized working face. The measurements of the borehole stress meter from eight boreholes at the four test stations are shown in Table 1 to Table 4.

Table 1 Stress meter observation data from the 3-m borehole

\begin{tabular}{cccc}
\hline No. & $\begin{array}{c}\text { Distance between } \\
\text { measuring point } \& \text { the } \\
\text { working face/m }\end{array}$ & $\begin{array}{c}\text { Transportation roadway } \\
\text { stress/MPa }\end{array}$ & $\begin{array}{c}\text { Stress of ventilation } \\
\text { roadway/MPa }\end{array}$ \\
\hline 1 & 2.8 & 7.3 & 5.7 \\
2 & 6.3 & 11.5 & 10.9 \\
3 & 9.0 & 23.6 & 21.2 \\
4 & 11.1 & 31.5 & 29.8 \\
5 & 16.2 & 32.3 & 32.6 \\
6 & 19.9 & 34.4 & 29.4 \\
7 & 26.2 & 25.3 & 26.2 \\
8 & 30.2 & 15.2 & 17.8 \\
9 & 40.4 & 17.3 & 13.9 \\
10 & 50.2 & 13.2 & 11.9 \\
11 & 60.3 & 10.0 & 10.7 \\
12 & 70.0 & 10.0 & 10.2 \\
\hline
\end{tabular}

Table 2 Stress meter observation data from the 6-m borehole

\begin{tabular}{cccc}
\hline No. & $\begin{array}{c}\text { Distance between } \\
\text { measuring point } \& \text { the } \\
\text { working face } / \mathrm{m}\end{array}$ & $\begin{array}{c}\text { Transportation roadway } \\
\text { stress/MPa }\end{array}$ & $\begin{array}{c}\text { Ventilation roadway } \\
\text { stress/MPa }\end{array}$ \\
\hline 1 & 3.1 & 6.2 & 7.1 \\
2 & 7.0 & 14.2 & 12.7 \\
3 & 9.1 & 21.0 & 27.2 \\
4 & 11.1 & 32.2 & 30.8 \\
5 & 16.1 & 34.3 & 35.2 \\
6 & 20.1 & 29.2 & 24.1 \\
7 & 25.3 & 26.2 & 26.4 \\
8 & 30.3 & 17.3 & 21.5 \\
9 & 40.2 & 15.2 & 19.9 \\
10 & 50.3 & 12.2 & 13.2 \\
11 & 60.2 & 10.3 & 11.0 \\
12 & 70.0 & 10.1 & 10.2 \\
\hline
\end{tabular}


Table 3 Stress meter observation data from the 12-m borehole

\begin{tabular}{cccc}
\hline No. & $\begin{array}{c}\text { Distance between } \\
\text { measuring point } \& \text { the } \\
\text { working face } / \mathrm{m}\end{array}$ & $\begin{array}{c}\text { Transportation roadway } \\
\text { stress/MPa }\end{array}$ & $\begin{array}{c}\text { Ventilation roadway } \\
\text { stress/MPa }\end{array}$ \\
\hline 1 & 2.9 & 6.5 & 5.9 \\
2 & 7.1 & 17.2 & 14.1 \\
3 & 9.3 & 26.2 & 23.8 \\
4 & 10.7 & 36.2 & 33.4 \\
5 & 15.3 & 37.6 & 35.9 \\
6 & 20.1 & 29.3 & 27.4 \\
7 & 24.1 & 21.3 & 24.3 \\
8 & 30.1 & 20.2 & 19.7 \\
9 & 40.6 & 18.2 & 16.1 \\
10 & 50.2 & 15.1 & 12.8 \\
11 & 60.0 & 12.3 & 10.7 \\
12 & 69.1 & 10.1 & 10.2 \\
\hline
\end{tabular}

Table 4 Stress meter observation data from the $15-\mathrm{m}$ borehole

\begin{tabular}{cccc}
\hline No. & $\begin{array}{c}\text { Distance between } \\
\text { measuring point } \& \text { the } \\
\text { working face } / \mathrm{m}\end{array}$ & $\begin{array}{c}\text { Transportation roadway } \\
\text { stress/MPa }\end{array}$ & $\begin{array}{c}\text { Ventilation roadway } \\
\text { stress/MPa }\end{array}$ \\
\hline 1 & 2.7 & 6.3 & 7.2 \\
2 & 7.2 & 16.6 & 13.8 \\
3 & 9.0 & 26.0 & 21.7 \\
4 & 10.2 & 34.3 & 29.8 \\
5 & 15.2 & 36.3 & 36.5 \\
6 & 19.2 & 30.2 & 30.7 \\
7 & 25.3 & 26.3 & 25.4 \\
8 & 30.4 & 19.2 & 21.9 \\
9 & 40.7 & 16.1 & 18.7 \\
10 & 50.5 & 13.1 & 14.8 \\
11 & 59.2 & 12.0 & 11.7 \\
12 & 69.7 & 10.7 & 10.3 \\
\hline
\end{tabular}

The borehole stress measurements of the advancing working face at different drilling depths are shown in Figure 4. 


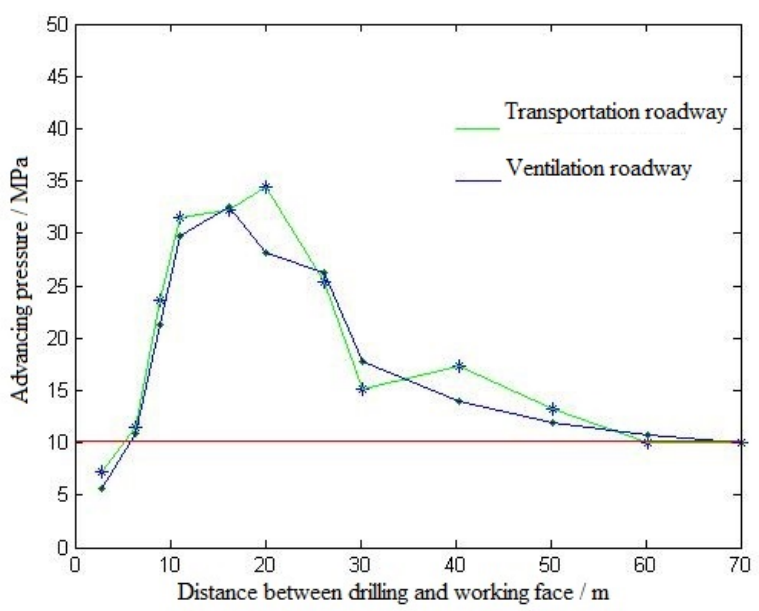

(a) Pressure in the 3-m borehole

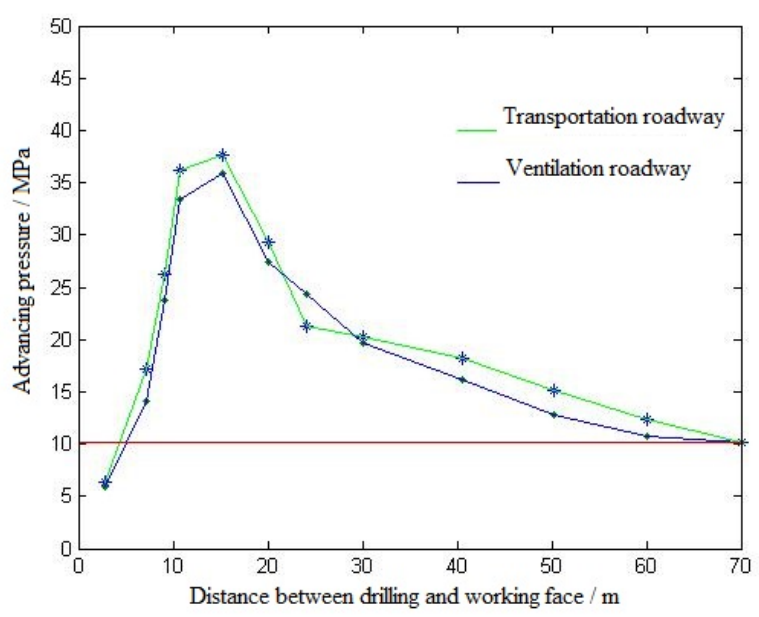

(c) Pressure in the 12-m borehole

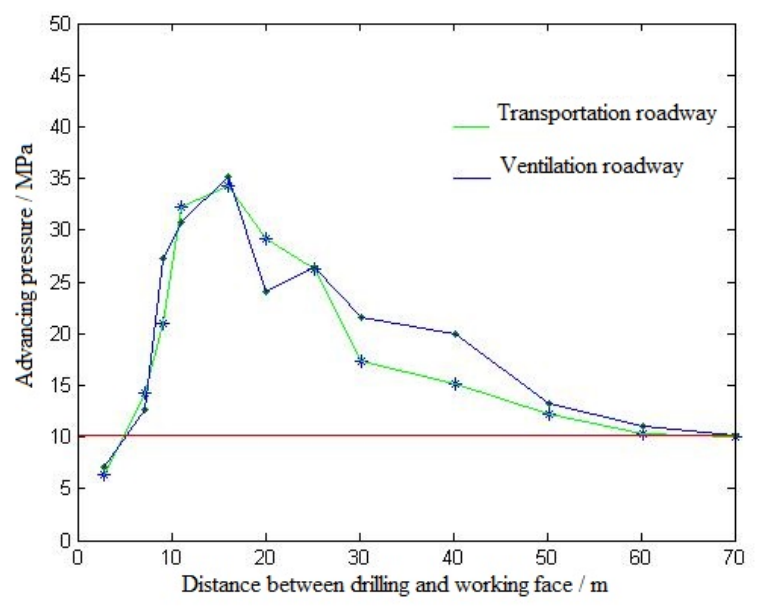

(b) Pressure in the 6-m borehole

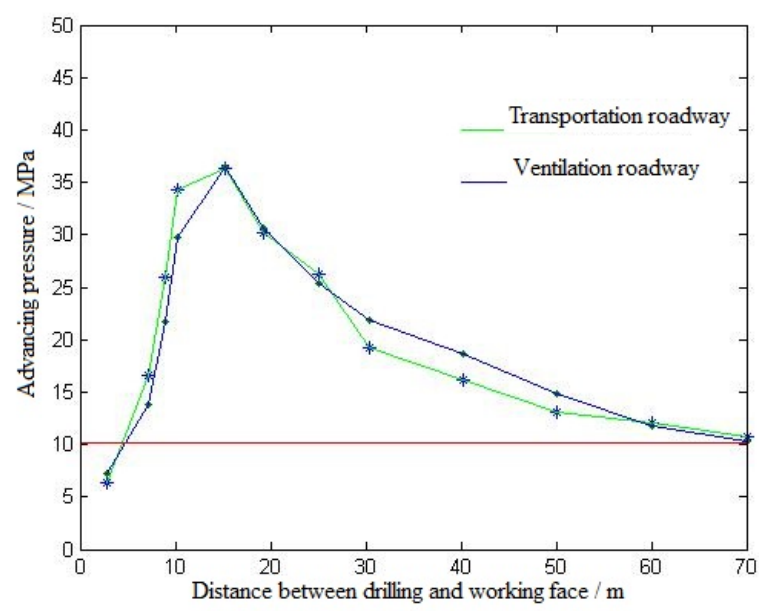

(d) Pressure in the 15-m borehole

Fig. 4 Advancing abutment pressure in different drilling depths

The red line in Figure 4 represents the original rock stress line, the green line represents the transportation roadway pressure, and the blue line represents the ventilation roadway pressure. The following is observed:

(i)When the distance between the fully-mechanized caving and drilling is about $65 \mathrm{~m}$, the borehole stress begins to exceed the rock stress, indicating that the advancing abutment pressure range of the j7401 fully-mechanized working face is about $65 \mathrm{~m}$.

(ii)The peak of the advancing pressure is between $15 \mathrm{~m}$ and $22 \mathrm{~m}$ in front of the working face, the peak range of the advancing pressure is $33 \mathrm{MPa} 39 \mathrm{MPa}$, and the peak of the advancing 
abutment pressure is 3.2 3.8 times that of the original rock stress.

\subsubsection{Variations in the surrounding rock deformation}

The observation data of the surrounding rock deformation are shown in Table 5 and Table 6 . The data were used to determine the influence range of the mining roadway on the fully-mechanized mining face.

Table 5 Observation data of the convergence of the ventilation roadway

\begin{tabular}{cccc}
\hline No. & $\begin{array}{c}\text { Distance between } \\
\text { measuring point \& the } \\
\text { working face/m }\end{array}$ & $\begin{array}{c}\text { Daily roof subsidence } \\
/ \mathrm{mm}\end{array}$ & $\begin{array}{c}\text { Daily convergence of both } \\
\text { sides/mm }\end{array}$ \\
\hline 1 & 0.8 & 11.2 & 11.6 \\
2 & 8.2 & 16.2 & 12.5 \\
3 & 10.2 & 18.3 & 7.1 \\
4 & 12.6 & 16.3 & 5.3 \\
5 & 16.3 & 7.2 & 4.7 \\
6 & 19.2 & 5.2 & 3.1 \\
7 & 25.1 & 2.2 & 1.0 \\
8 & 35.2 & 1.2 & 0.8 \\
9 & 45.1 & 0.5 & 0.2 \\
10 & 55.2 & 0.2 & 0.2 \\
11 & 60.0 & 0.0 & 0.0 \\
12 & 70.0 & 0.1 & 0.0 \\
\hline
\end{tabular}

Table 6 Observation data of the convergence of the transportation roadway

\begin{tabular}{cccc}
\hline No. & $\begin{array}{c}\text { Distance between } \\
\text { measuring point } \& \text { the } \\
\text { working face } / \mathrm{m}\end{array}$ & $\begin{array}{c}\text { Daily roof subsidence } \\
/ \mathrm{mm}\end{array}$ & $\begin{array}{c}\text { Daily convergence of both } \\
\text { sides } / \mathrm{mm}\end{array}$ \\
\hline 1 & 0.8 & 9.2 & 13.2 \\
2 & 4.2 & 11.2 & 14.1 \\
3 & 6.5 & 11.4 & 14.9 \\
4 & 10.4 & 10.3 & 11.8 \\
5 & 13.7 & 8.3 & 6.1 \\
6 & 17.2 & 6.2 & 2.4 \\
7 & 20.3 & 3.0 & 3.0 \\
8 & 27.0 & 2.0 & 0.8 \\
9 & 36.8 & 0.9 & 0.4 \\
10 & 49.0 & 0.5 & 0.6 \\
\hline
\end{tabular}


We used the data in Table 5 and Table 6 to plot the velocity changes in the surrounding rock deformation of the transportation roadway and ventilation roadway (Figure 5).

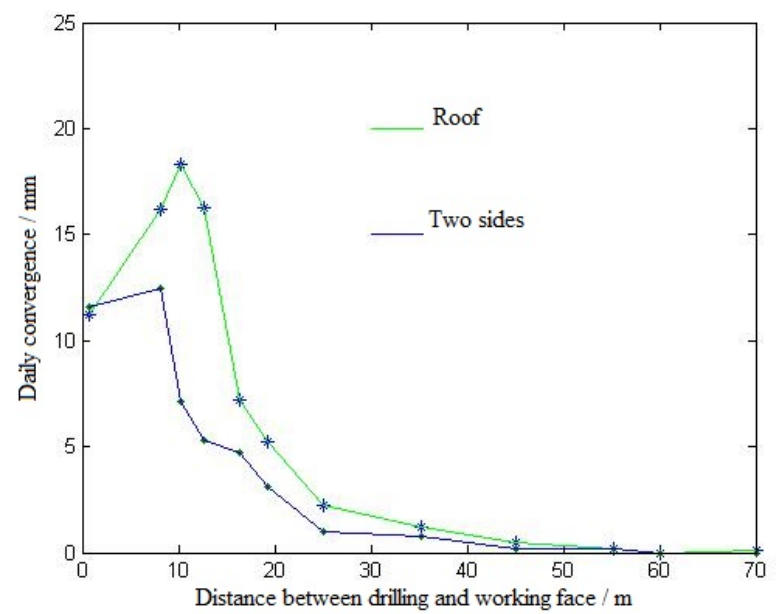

(a) Ventilation roadway

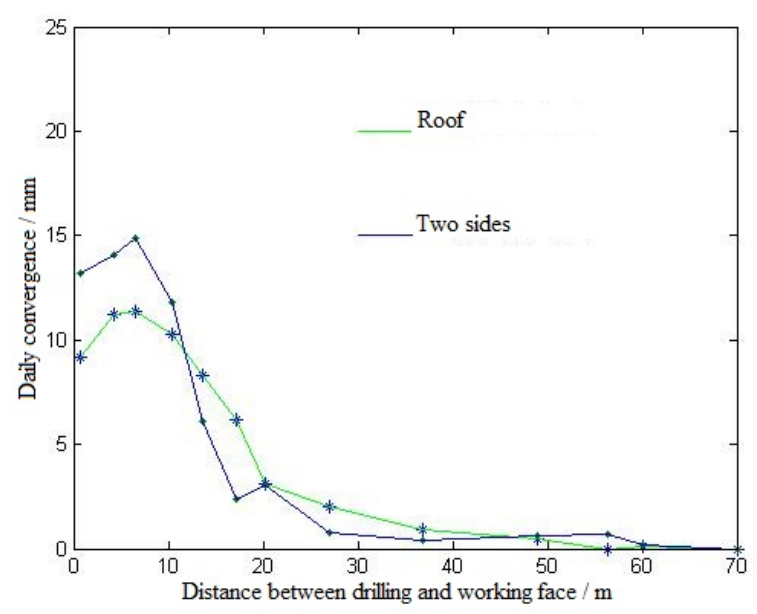

(b) Transportation roadway

Fig. 5 Velocity changes in the surrounding rock of the ventilation roadway (a) and transportation roadway (b)

The following results were observed:

(i) In front of the fully mechanized working face, the roof activity is intense at $0 \sim 20 \mathrm{~m}$. The maximum daily subsidence rate of the roof is $18 \mathrm{~mm}$ in the range of $5-11 \mathrm{~m}$ in the front of the working face. The daily convergence of the roof subsidence at $20 \mathrm{~m}$ in front of the working face is less than $5 \mathrm{~mm}$ for the ventilation roadway and less than $3 \mathrm{~mm}$ for the transport roadway. The daily convergence beyond $60 \mathrm{~m}$ in front of the working face is close to 0 .

(ii) In the range of $0 \sim 20 \mathrm{~m}$ in front of the fully-mechanized working face, the convergence of the two sides is very large. The maximum speed of the two groups of daily convergence at $6 \mathrm{~m} \sim 8 \mathrm{~m}$ in front of the working face is $19.4 \mathrm{~mm}$, and the maximum daily convergence of the two groups is 14.9 $\mathrm{mm}$. The daily convergence values in the range of $20 \mathrm{~m} \sim 60 \mathrm{~m}$ in front of the working face are less than $3 \mathrm{~mm}$. The daily convergence in the front of the working face beyond $60 \mathrm{~m}$ is close to 0 .

These results indicate that the deformation of the surrounding rock is very large in the range of 
$0 \sim 20 \mathrm{~m}$ in the front of the working face, is weak in the range of $20 \mathrm{~m} \sim 60 \mathrm{~m}$, and the surrounding rock is basically unaffected by mining beyond $60 \mathrm{~m}$.

\subsubsection{Relationship between advancing abutment pressure and roadway deformation}

The changes in the advancing abutment pressure at different positions in front of the fully-mechanized working face were determined using the data shown in Table $1 \sim$ Table 4 and least squares fitting. The data for the transport roadway and ventilation roadway are analyzed together. The 96 data points in the four tables $\left(x_{i}, y_{i}\right),(i=1,2, \ldots, 96)$ were used to find the approximation function $y=S(x)$. The principle of this method is to minimize the sum of squares between the fitted value and the actual value to determine the approximation function of $f(x)$ in $\Phi=\operatorname{span}\left\{\phi_{0}(x), \phi_{1}(x), \ldots, \phi_{n}(x)\right\}$ (Where $\phi_{i}(x)$ is the $i$ vector function of $x$ ) to find $a_{k}(k=0,1, \ldots, n)$. Let $S(x)=\sum_{k=0}^{n} a_{k} \phi_{k}$ in $\Phi$ space be the best approximation function for $f(x)^{[18,19]}$.

We used the distance between the measuring point and the working face (Table 1 Table 4 ) as the independent variable and the advancing abutment pressure as the dependent variable; the fitted function curve is shown in Figure 6.

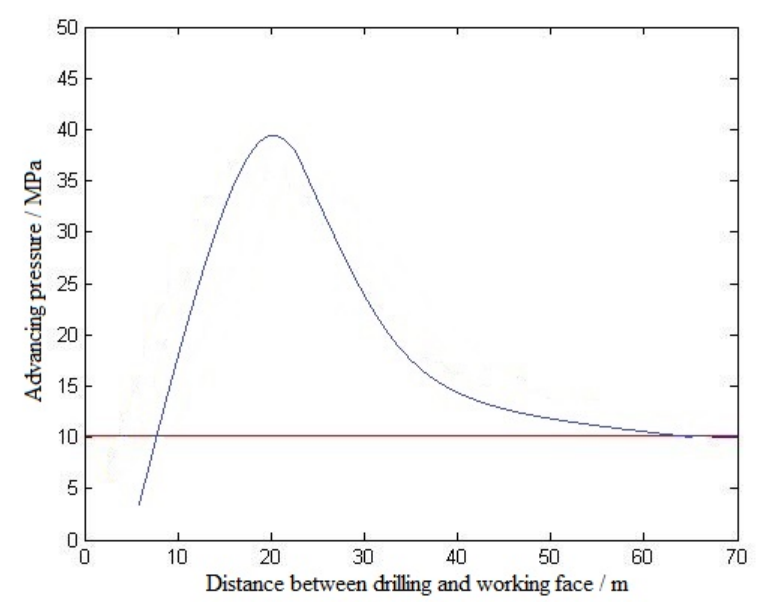

Fig. 6 Fitted curve of the advancing abutment pressure

The following is observed in Figure 6:

(i) The advancing abutment pressure gradually increases in the range of $0 \mathrm{~m}$ to $19.8 \mathrm{~m}$ in the 
front of the working face and is equal to the original rock stress at $0.8 \mathrm{~m}$.

(ii) The peak value of the advancing abutment pressure is $39.4 \mathrm{MPa}$ and occurs at $19.8 \mathrm{~m}$ in front of the working face.

(iii) The advancing abutment pressure decreases gradually in the range of $19.8 \sim 65 \mathrm{~m}$ in front of the working face. Beyond $65 \mathrm{~m}$, the pressure is the same as that of the original rock stress.

The data in Table 5 and Table 6 are also analyzed using the least squares fitting method. We made no distinction between the convergences of the two sides and the roof subsidence and considered only the daily roadway deformation. The measuring point and working face distance (Table 5 and Table 6) are used as independent variables and the daily deformation of the roadway in front of the working face is the dependent variable, as is shown in Figure 7.

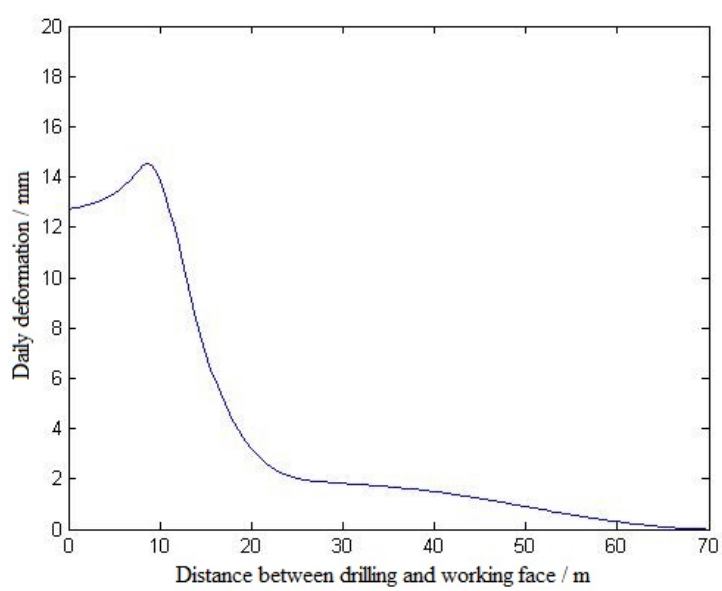

Fig. 7 Fitted curve of the daily deformation of the roadway in front of the working face

The following is observed in Figure 7:

(i) The maximum daily deformation occurs at $8.9 \mathrm{~m}$ in front of the working face and the daily deformation is larger than $12 \mathrm{~mm}$ in the range of $0 \sim 8.9 \mathrm{~m}$, which is the rapid deformation stage.

(ii) In the range of 8.9 to $20.1 \mathrm{~m}$ the daily deformation of the roadway decreases from $14.5 \mathrm{~mm}$ to about $3 \mathrm{~mm}$; this is the deceleration deformation stage.

(iii) The daily deformation of the roadway beyond $20.1 \mathrm{~m}$ in front of the working face is very small. The deformation is zero at $65 \mathrm{~m}$. In the range of $20.1 \sim 65 \mathrm{~m}$, the daily deformation of the 
roadway decreases slowly from $3 \mathrm{~mm}$ to $0 \mathrm{~mm}$; this is the stable small deformation stage.

A comparison of the results in Figure 6 and Figure 7 indicates that the intersection of the advancing abutment pressure curve and the original rock stress curve is located at $8.1 \mathrm{~m}$ ahead of the working face. The boundary between the rapid deformation stage and the deceleration deformation stage of the roadway is $8.9 \mathrm{~m}$ in front of the working face and the distance between the stages is 0.8 $\mathrm{m}$. The peak position of the advancing abutment pressure is at $19.8 \mathrm{~m}$. The boundary between the deceleration deformation stage and the stable small deformation stage of the roadway is at $20.1 \mathrm{~m}$ and the distance between the stages is $0.3 \mathrm{~m}$.

Based on the results of the theoretical analysis and the field measurement, we obtained the relationship between the advancing abutment pressure and the surrounding rock deformation stage of the roadway (Figure 8).

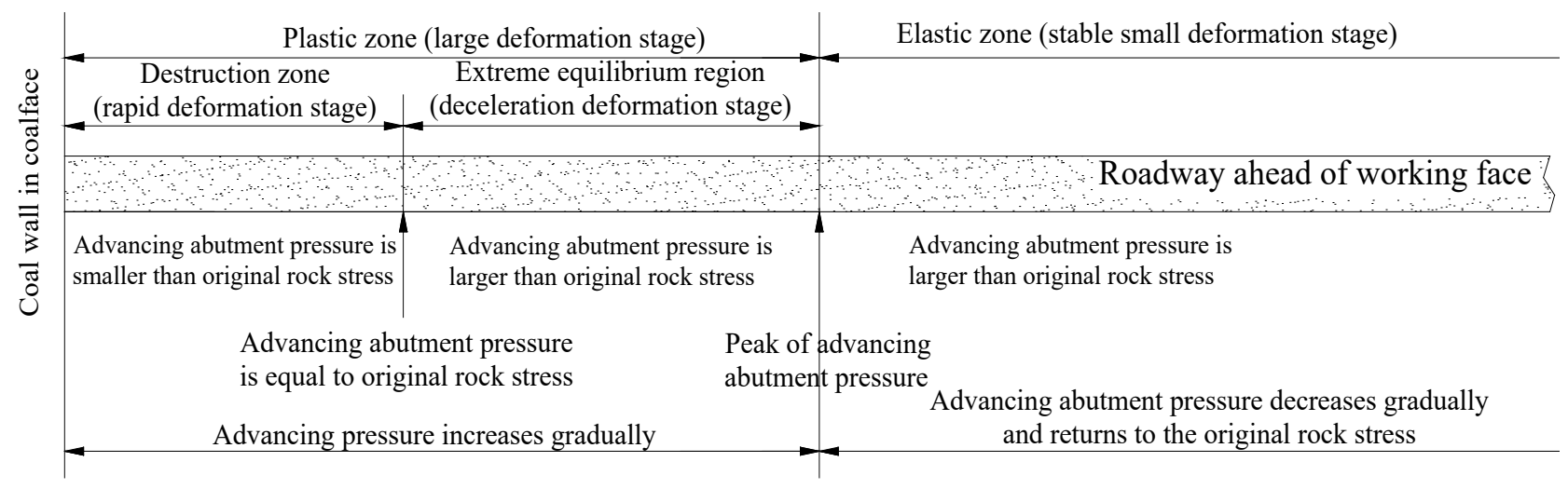

Fig. 8 Relationship between the advancing abutment pressure and the surrounding rock deformation of a roadway

The results show that the boundary between the failure zone (rapid deformation stage) and the limit equilibrium zone (deceleration deformation stage) is the intersection of the advancing abutment pressure curve and the original rock stress line. The damaged area (rapid deformation phase) and the limit equilibrium area (slow deformation stage) constitute the plastic zone (large deformation stage). The boundary between the plastic zone (large deformation stage) and elastic zone (stable small deformation stage) is located at the peak value of the advancing abutment pressure. 


\section{Conclusions}

A theoretical analysis and field measurements are used to analyze the relationship between the advancing abutment pressure and the surrounding rock deformation characteristics of the roadway of the j7401 fully-mechanized working face. The following conclusions are drawn:

We put forward a method of separating the surrounding rock deformation of the roadway in front of the working face into three stages: the rapid deformation stage, the deceleration deformation stage, and the stable small deformation stage. The rapid deformation stage and deceleration deformation stage occur in the plastic zone of the surrounding rock deformation and represent the large deformation stage. The stable small deformation stage occurs in the elastic zone of the surrounding rock deformation.

The relationship between the advancing abutment pressure and the deformation stage of the surrounding rock of the roadway is determined by integrating the results of the theoretical analysis and field measurements. The boundary between the failure zone (rapid deformation stage) and the limit equilibrium zone (deceleration deformation stage) is the intersection of the advancing abutment pressure curve and the original rock stress curve. The boundary between the plastic zone (large deformation stage) and the elastic zone (stable small deformation stage) is located at the peak value of the advancing abutment pressure.

\section{References}

[1] Qian Minggao, Shi Pingwu. (2003). "Mine pressure and rock control". China university of mining and technology press,Beijing.pp.65-119.

[2] Hou Chaojiong. (2012.10). "Roadway surrounding rock control". China university of mining and technology press, Beijing.

[3] Xu Jialin, Ju Jinfeng.(2011,08). "Structural morphology of key stratum and it's influence strata behaviors in fully-mechanized face with super-large mining height". Chinese Journal of Rock Mechanics and Engineering, Beijing, pp.1547-1556 
[4] Xu Jialin,Zhu Weibing,Wang Xiaozhen,etc al. (2012,02)“Influencing mechanism of gully terrain on ground pressure behaviors in shallow seam longwall mining".Journal of China coal society, China, pp.179-185.

[5] Wang Jiachen, Yang Shengli, Yang Baogui, etc al.(2012) "Simulation experiment of overlying strata movement features of longwall with gangue backfill mining". Journal of China coal society, China, pp.1256-1262.

[6] Wang Jiachen, Zhang Jinwang.(2015,03) "BBR study of top-coal drawing law in longwall top-coal caving mining". Journal of China coal society, China,pp. 487-493.

[7] Zhang Hong-wei1, Rong Hai, Chen Jian-qiang,etc al. (2015,12)“Risk assessment of rockburst based on geo-dynamic division method in suberect and extremely thick coal seam". Journal of China coal society, China,pp. 2755-2762.

[8] Zhang Hongwei, Zhu Feng, Han Jun,etc al. $(2016,03)$ “Geological dynamic conditions and forecast technology for rock bursts". Journal of China coal society. pp.545-551.

[9] Liu Gang, Zhao Jian, Song Hongwei. (2013)“Analysis on roadway stability in jointed rock mass”. Journal of central south university(science and technology), vol,44, no.07,pp.2910-2918.

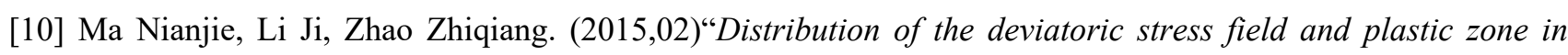
circular roadway surrounding rock". Journal of China university of mining\& technology .pp.206-213.

[11] Ma Nianjie, Zhao Xidong, Zhao Zhiqiang, etc al. $(2015,10)$ “Stability analysis and control technology of mine roadway roof in deep mining". Journal of China coal society.pp.2287-2295.

[12] Meng Xiangrui, Peng Rui, Zhao Guangming, et al. (2017)“Roadway engineering mechanical properties and roadway structural instability mechanisms in deep wells". KSCE Journal of Civil Engineering.pp.1-13. DOI:10.1007/s12205-017-1298-y.

[13] Kang Hongpu , Yan Lixin, Guo Xiangping, etc al. $(2012,10)^{“ C}$ Characteristics surrounding rock deformation and reinforcement technology of retained entry in working face with multi-entry layout.Chinese Journal of Rock Mechanics and Engineering".pp.2022-2036.

[14] Gou Panfeng, Xin Yajun. (2013,12)“Rheological control mechanical analyticity of surrounding rock anchorage body in deep roadway".Journal of China coal society.pp.2119-2125.

[15] Gou Panfeng, Xin Ya-jun, Shen Yan-mei, etc al. (2013,01)“Stability analysis and mechanism of two-side anchorage body in deep mine gateway".Journal of Mining \& Safety Engineering.pp.7-13.

[16] Zhao Guozhen.(2014). "Deformation Mechanism and Control of Thick Coal-seam Roadway under Thick Loose Layer with Fully Mechanized Sub-level Caving Mining". China university of mining \& technology. 
[17] Yang Xiaoli, Wang Zuowei. (2010)“Limit analysis of earch pressure on shallow tunnel using nonliure failure crierion". Journal of central south university(science and technology),vol,41,no.01, pp.299-302.

[18] Li Zhe, Ding Zhenliang, Yuan Feng. (2008,05)“Subpixel Algorithm Basedon Level Interpolationand Least Squares Fiting”.Journal of Nanjing university of science and technology(Natural Science).pp.615-618.

[19] Chen YueNing, Xu Zheng,Zhao SuLing,etc al. (2010,11)“Research on least-squares fitting calculation of the field-effect mobilityJun".Acta Physica Sinica. pp.8113-8117. 
Figures

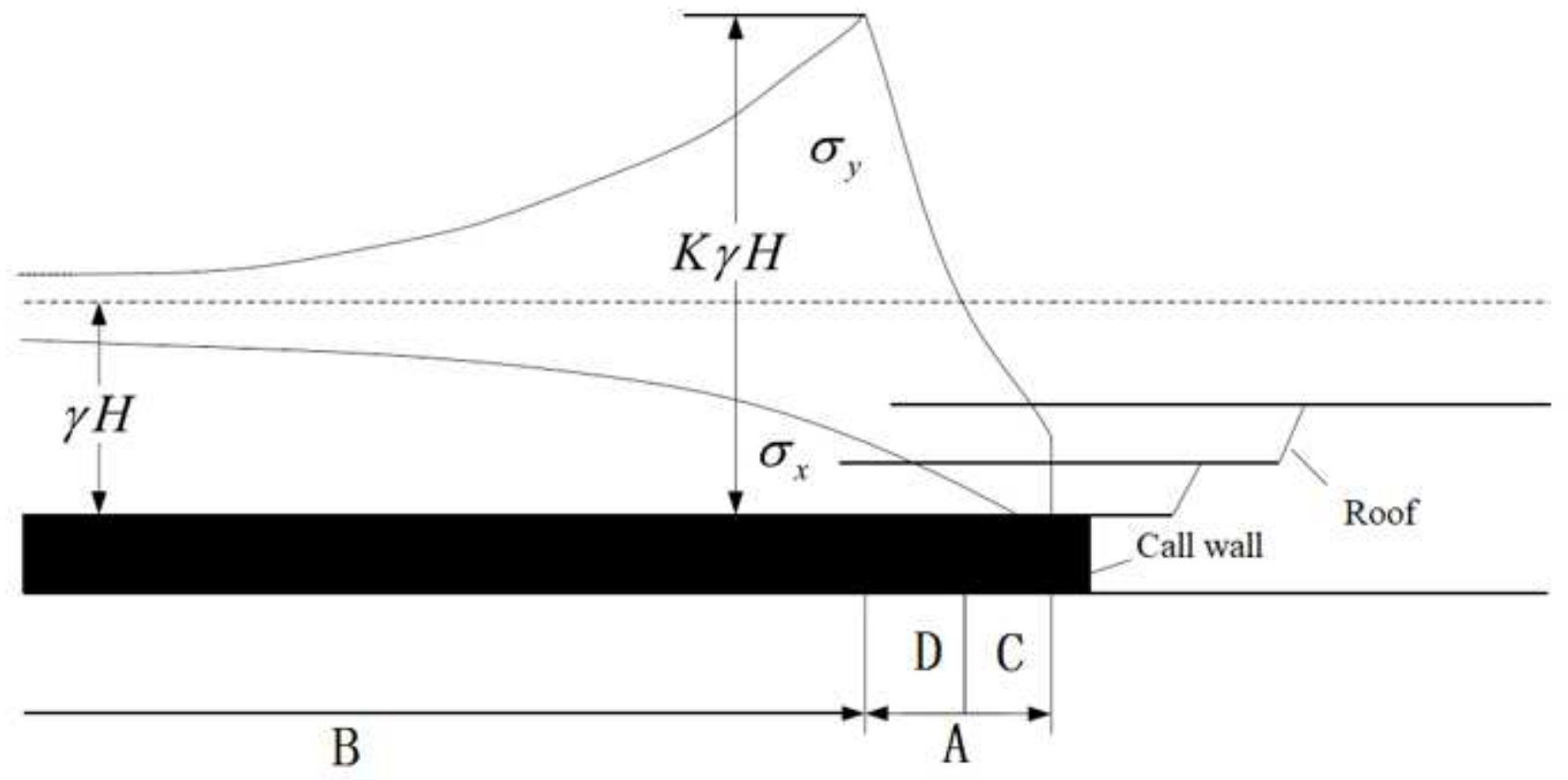

Figure 1

Diagram of the advancing abutment pressure

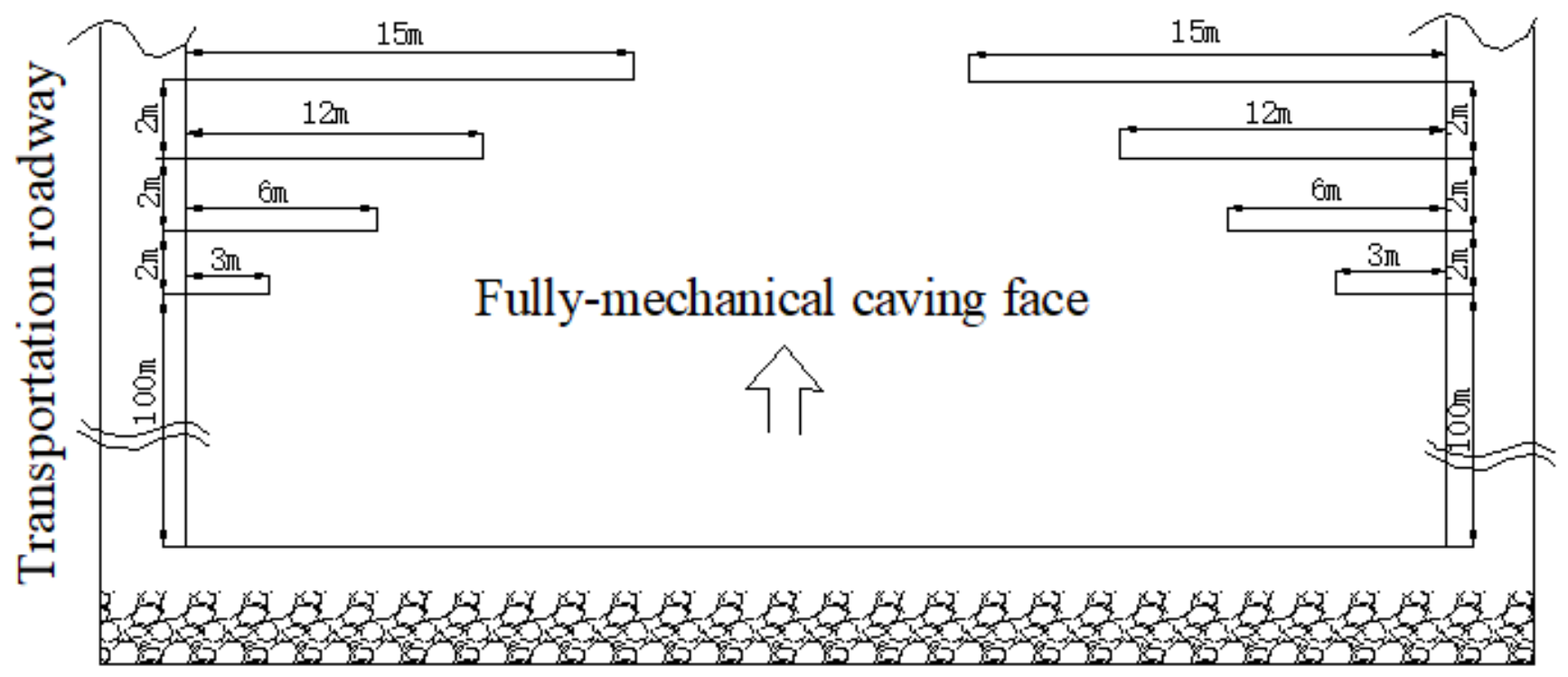

Figure 2

Diagram of the stress drill point layout 


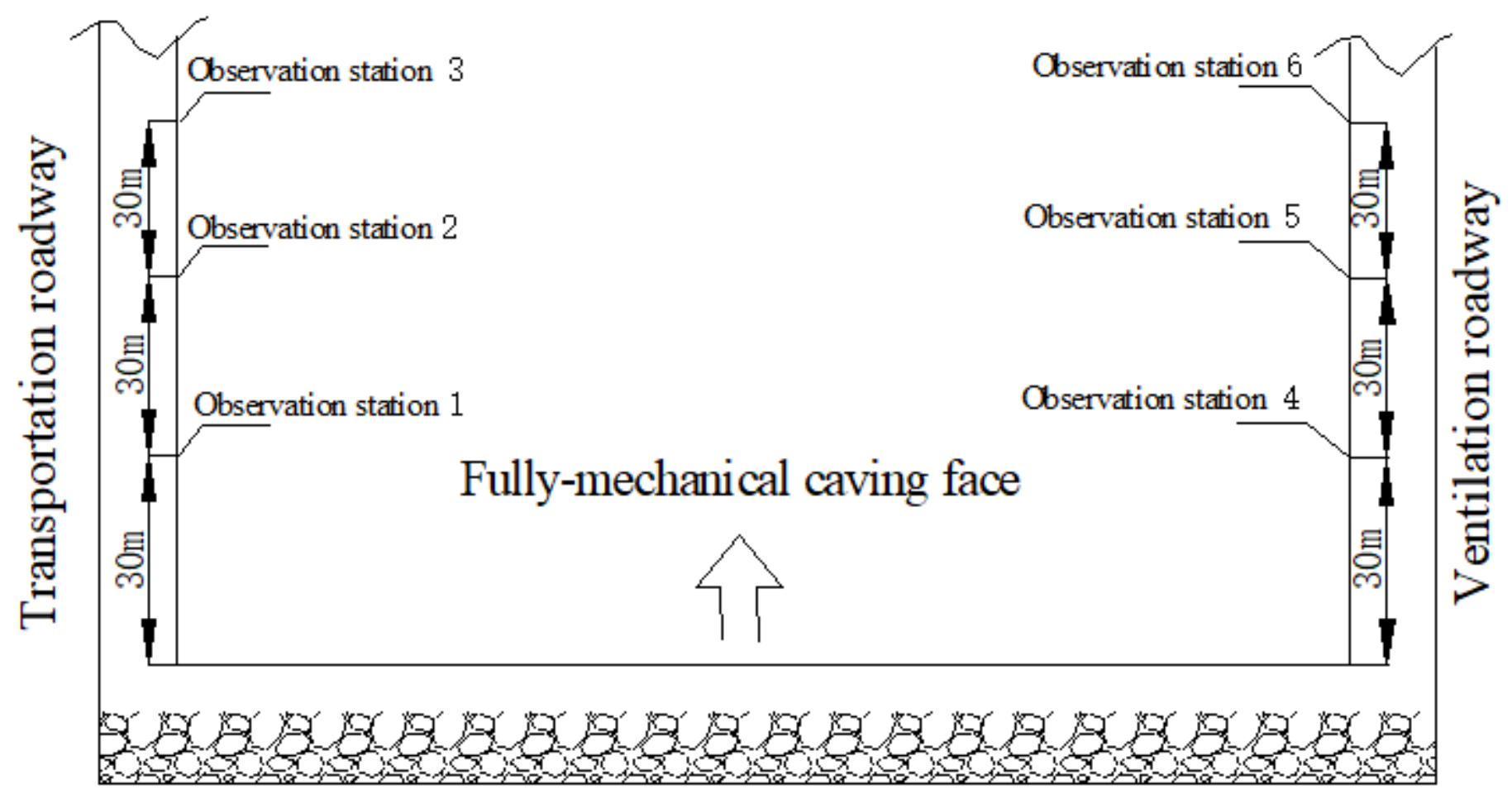

Figure 3

Diagram of the roadway station layout 


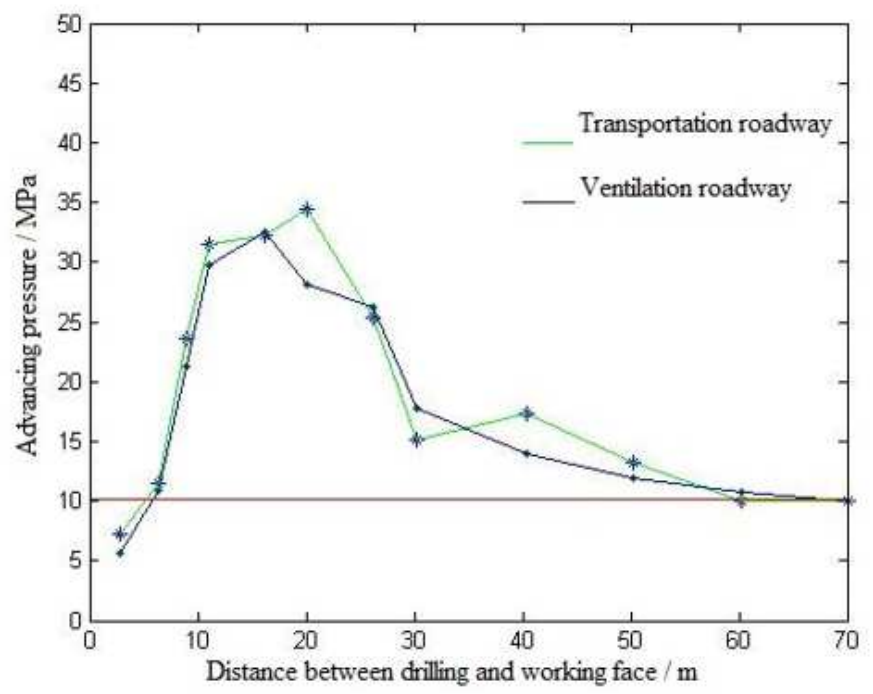

(a) Pressure in the 3-m borehole

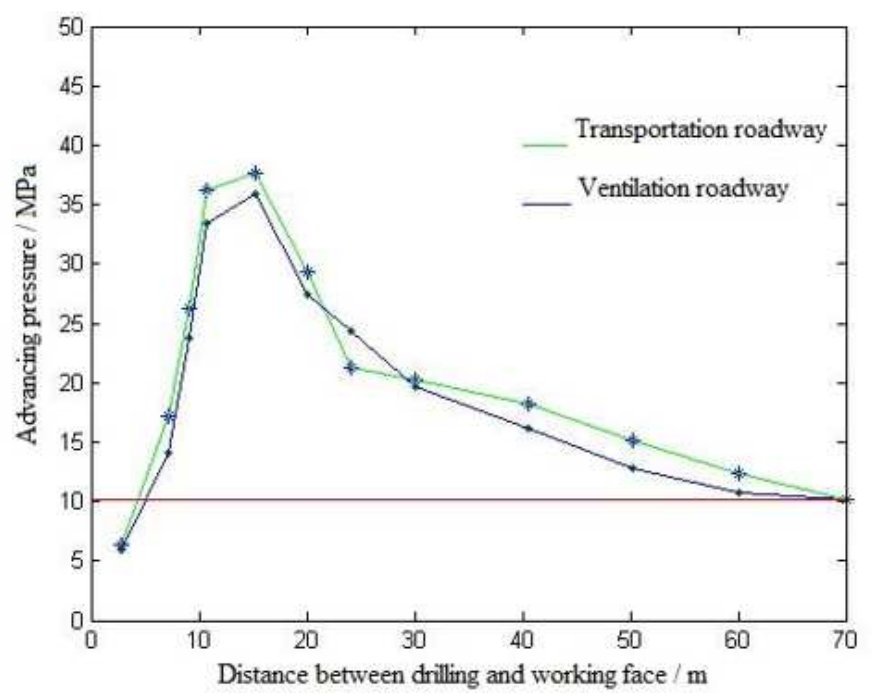

(c) Pressure in the 12-m borehole

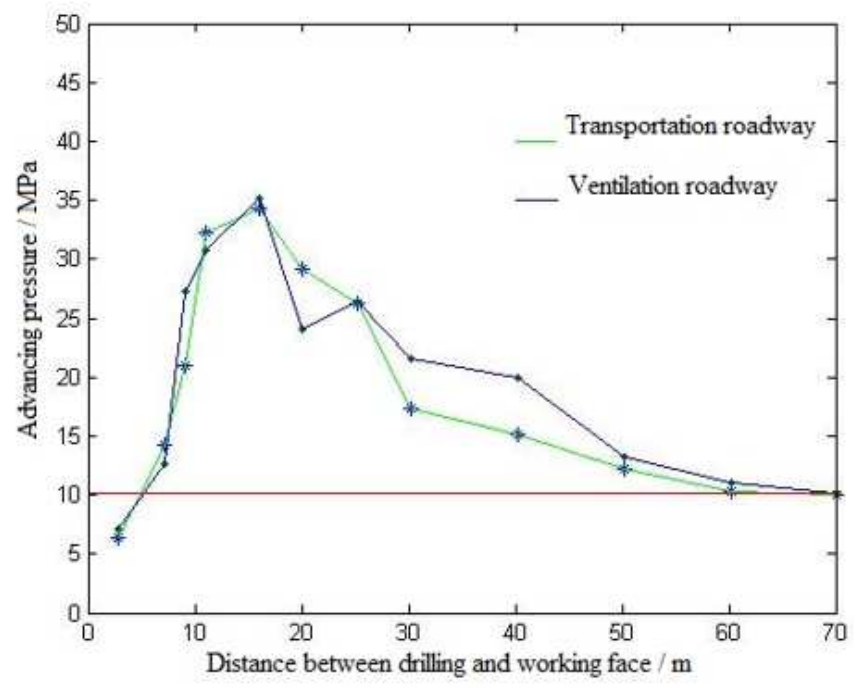

(b) Pressure in the 6-m borehole

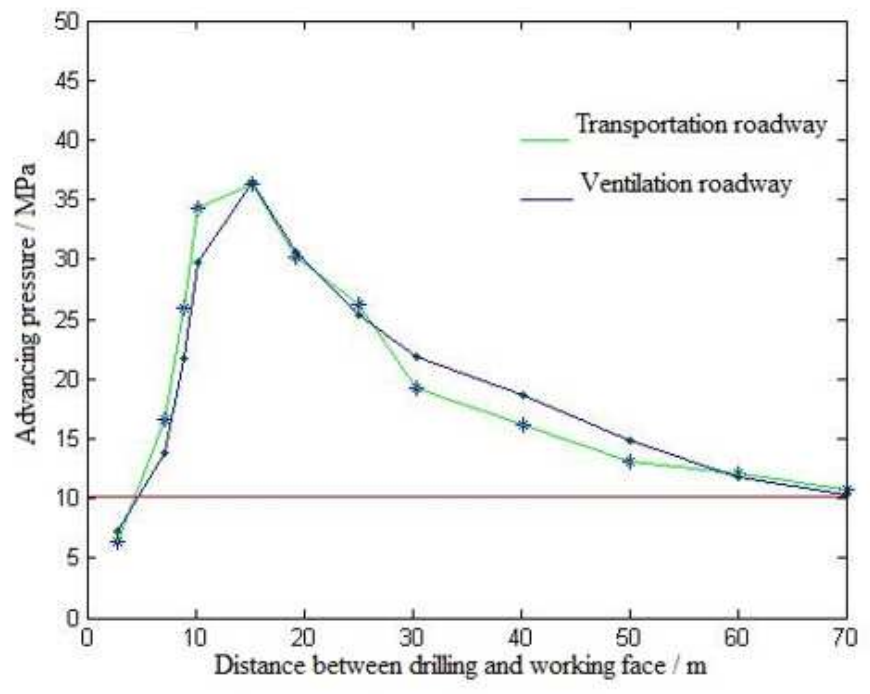

(d) Pressure in the $15-\mathrm{m}$ borehole

\section{Figure 4}

Advancing abutment pressure in different drilling depths 


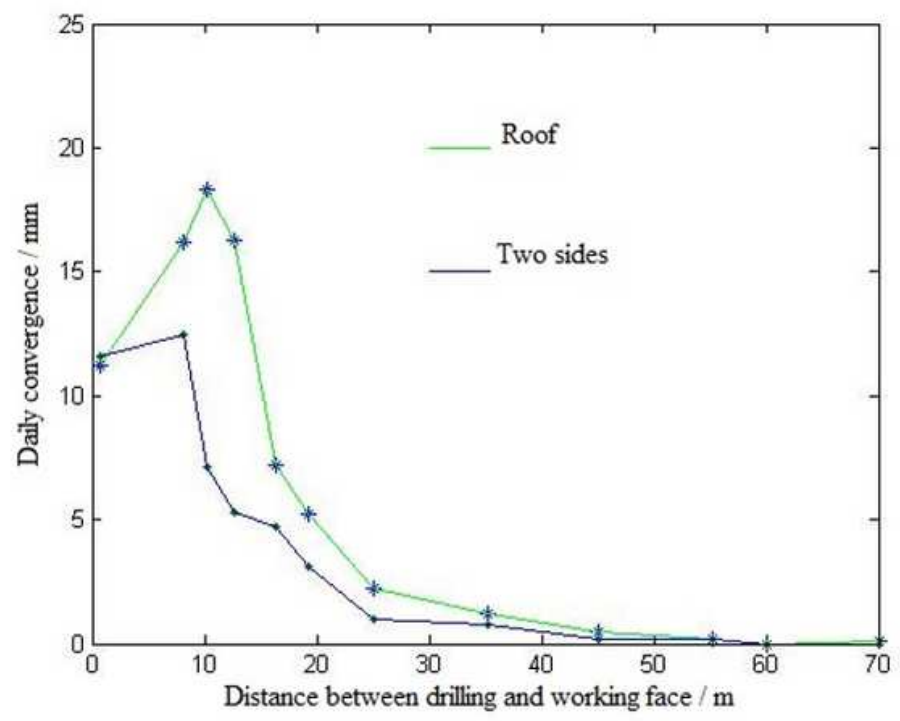

(a) Ventilation roadway

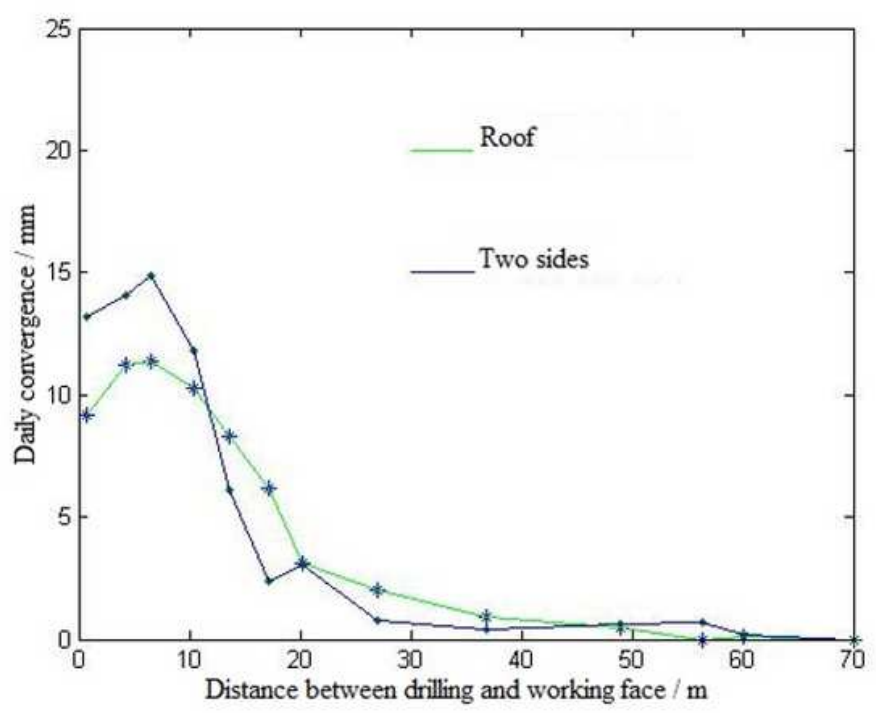

(b) Transportation roadway

\section{Figure 5}

Velocity changes in the surrounding rock of the ventilation roadway (a) and transportation roadway (b)

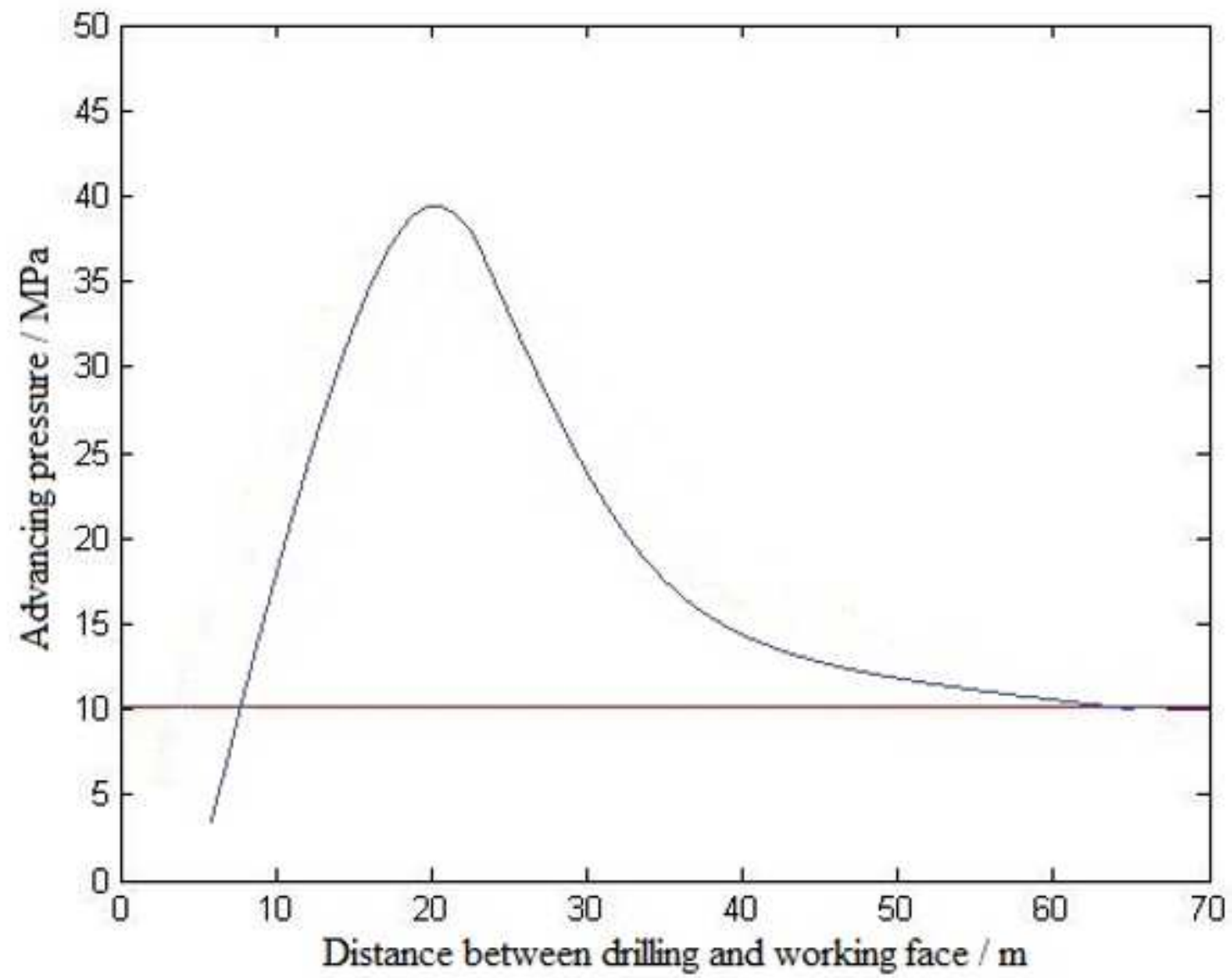

Figure 6 


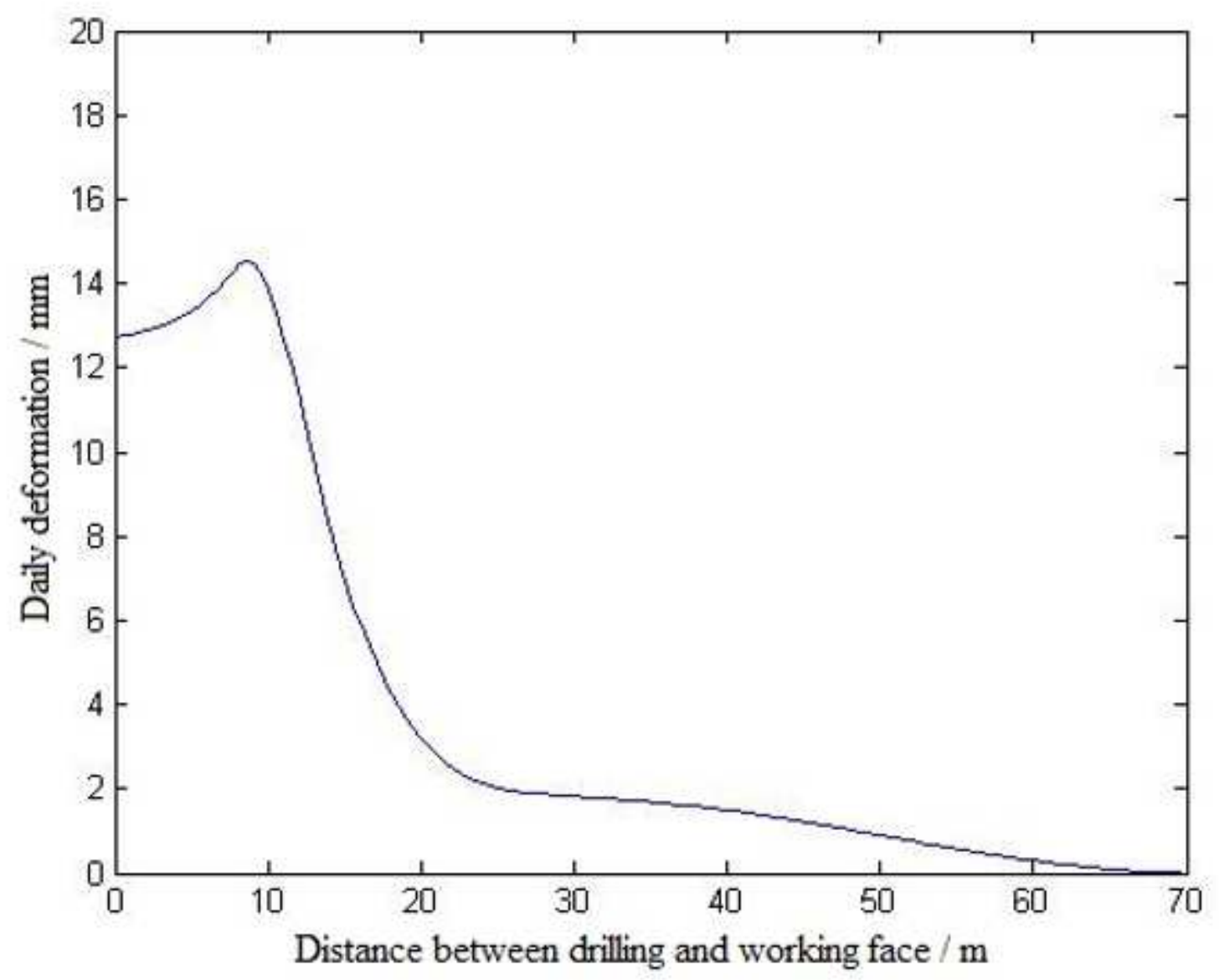

Figure 7

Fitted curve of the daily deformation of the roadway in front of the working face

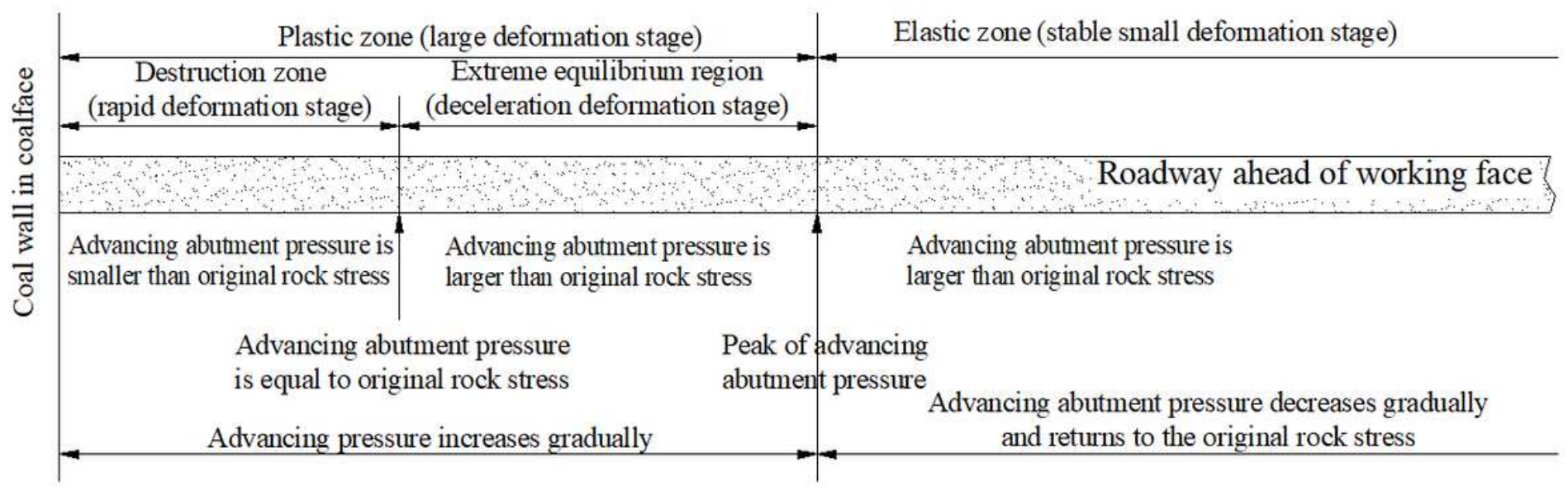

\section{Figure 8}

Relationship between the advancing abutment pressure and the surrounding rock deformation of a roadway 